\title{
The genetic consequences of captive breeding, environmental change and human exploitation in the endangered peninsular pronghorn
}

Anastasia Klimova ( $\sim$ anastasia_aleksandrovan@hotmail.com )

ACTG Molecular Solutions

Victor Sánchez-Sotomayor

National Commission of Natural Protected Areas (CONANP)

Jesus Gutiérrez Rivera

Centro de Investigaciones Biológicas del Noroeste Baja California Sur

Joseph Ivan Hoffman

Bielefeld University

Research Article

Keywords:

Posted Date: February 17th, 2022

DOI: https://doi.org/10.21203/rs.3.rs-1310394/v1

License: (c) (i) This work is licensed under a Creative Commons Attribution 4.0 International License.

Read Full License 


\section{Abstract}

Endangered species with small population sizes are susceptible to genetic erosion, which can be detrimental to long-term persistence. Consequently, monitoring and mitigating the loss of genetic diversity are key to successful conservation. The peninsular pronghorn (Antilocapra americana peninsularis) is an endangered pronghorn subspecies that is almost entirely held in captivity. Captive breeding has increased the number of pronghorns from 25 founders in 1997 to around 700 individuals today, but it is unclear how the genetic diversity of the captive herd may have changed over time. We therefore generated and analysed microsatellite data spanning 2009-2021. We found a decline in heterozygosity and an increase in the proportion of inbred individuals over time. However, these trends appear to have abated in response to a genetically informed selective breeding attempt undertaken in 2018. We also reconstructed the recent demographic history of the peninsular pronghorn, revealing two sequential population declines putatively linked to the desertification of the Baja California peninsula around 6,000 years ago, and hunting and habitat loss around 500 years ago. Our results provide insights into the genetic diversity of an endangered antelope and highlight the potential for selective breeding to have positive conservation outcomes.

\section{Introduction}

Many species have experienced severe declines over the past two centuries as a result of growing anthropogenic pressures including direct exploitation, habitat destruction and climate change ${ }^{1,2,3}$. Some authors have even argued that Earth's biodiversity is entering a sixth mass extinction event, characterised by the unprecedented loss of diversity at all levels ${ }^{4,5,6}$. Consequently, nowadays the persistence of many species is critically dependent on intensive management actions such as captive breeding, habitat restoration and reintroduction programs.

For many species, captive management has been the only option for survival ${ }^{7}$. For example, species like the Kakapo (Strigops habroptilus), Przewalski's horse (Equus przewalskii) and giant Galapagos tortoise (Chelonoidis niger), among many others, would have gone extinct without human intervention and ex situ management ${ }^{8,9,10}$. Captive breeding is frequently used for the preservation of threatened species and, in

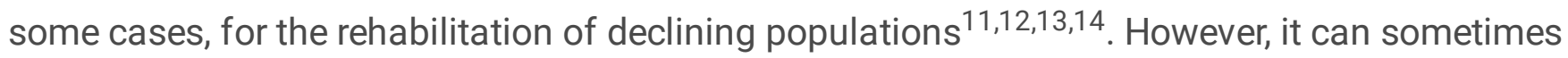
inadvertently lead to genetic or behavioural changes that are not always beneficial ${ }^{15}$. For example, when selective pressures in captivity differ to those that are usually encountered by a species in the wild, maladaptive alleles or behaviours can rise to high frequency in captive populations, which can compromise the survival of individuals after they are reintroduced into the wild ${ }^{16,17}$. Furthermore, in small captive herds, strong genetic drift and the increased probability of mating between close relatives can decrease heterozygosity and lead to inbreeding depression ${ }^{18,19,20,21,22}$. The fitness costs associated with inbreeding are manifest across taxonomic groups and include negative effects on litter size, longevity, female reproduction, male fertility and weight, in addition to hereditary defects $23,24,25,26$, all of which can have a strong impact on population viability. 
Given that conserving genetic diversity and minimising inbreeding are important goals of most if not all captive breeding programmes ${ }^{27,28}$ and reduced genetic diversity has been associated with increased extinction risk and reduced adaptive potential $29,30,31$, knowledge of the effects of captive breeding on genetic diversity is crucial. However, genetic time-series data are still uncommon for both captive and wild populations $32,33,34,35$. Temporal data can be especially informative about changes in key genetic characteristics of a population such as allelic richness, heterozygosity and the effective population size $\left(N_{\mathrm{e}}\right)$; measures that reflect a combination of the speed of allele frequency change through genetic drift, the efficacy of selection and expected genetic diversity levels for selectively neutral loci ${ }^{36,37}$.

The pronghorn (Antilocapra americana) is the only extant species of the North American family Antilocapridae ${ }^{38,39}$. Pronghorns are thought to have been historically abundant, with documents from the 1800s suggesting that roughly 30-40 million individuals inhabited North America prior to the westward settlement of humans on the continent ${ }^{40,41}$. Nevertheless, current pronghorn numbers have been severely affected by habitat fragmentation and overhunting, with many populations having declined or disappeared entirely ${ }^{42,43,44}$. Nowadays, four pronghorn subspecies are recognized: the american pronghorn (A. a. americana), the sonoran pronghorn ( $A$. a. sonoriensis), the peninsular pronghorn $(A . a$. peninsularis) and the mexican pronghorn (A. a. mexicana) ${ }^{45}$. The american pronghorn is the most widespread subspecies, with the sonoran, peninsular and mexican subspecies occupying more peripheral southerly areas ${ }^{40,45,44}$. Of these subspecies, the peninsular and sonoran are currently under national and international protection ${ }^{46,47,48}$. Overall, the pronghorn is one of the many species currently undergoing captive breeding and translocation, with breeding programs active in the USA and in Mexico $49,50,51$.

As with all of the pronghorn subspecies, wild populations of the peninsular pronghorn have declined substantially since the arrival of the fist Spanish settlers ${ }^{51}$. By the beginning of the twentieth century, the peninsular pronghorn was thought to number fewer than 1,000 individuals ${ }^{40}$. These numbers have since fallen to fewer than a hundred individuals in the $1980 \mathrm{~s}^{42,51,52,53}$. In the face of imminent extinction, a captive breeding program for the peninsular pronghorn was established by the Peninsular Pronghorn Species Recovery Programme ${ }^{51}$. This commenced in 1997 at the Vizcaino Biosphere Reserve, Mexico, with 25 wild-caught adults and fawns being introduced to the breeding facilities during the first six years of the programme ${ }^{49}$. Since then, the captive population has grown rapidly.

Currently, the animals are held in three management stations, with an additional six small populations held by a consortium of zoos in the Southwestern USA ${ }^{53}$. The main conservation area encompasses over 54,000 ha located in two protected natural areas: the El Vizcaíno Biosphere Reserve and the Valle de los Cirios Flora and Fauna Protection Area. Some of the individuals are allowed to roam freely over the protected areas and are provided only with supplementary feeding and water during the dry season ${ }^{53}$. Other animals, mainly the breeding herd and pregnant females, are managed in smaller pens with yearround supplemental food and water. In 2018, a genetically informed selective breeding attempt was undertaken. A selection of young but sexually mature males and females were microsatellite genotyped 
(2018 cohort, this paper) and a breeding plan was developed that focused on minimizing the relatedness of the breeding partners. Animals with rare alleles were also prioritized for breeding in order to mitigate the loss of genetic diversity. Therefore, the peninsula pronghorn conservation program represents an example of successful ongoing species recovery, while also providing an opportunity to investigate the genetic outcomes of selective breeding.

Previous population genetic studies of pronghorns uncovered moderate to high levels of genetic diversity in the american subspecies $45,54,55,56,57$, while genetic diversity appears to be somewhat lower for the sonoran ${ }^{54,58}$ and peninsular pronghorn subspecies ${ }^{58,59}$. Moreover, the American subspecies shows little evidence of population genetic structure ${ }^{57}$ while population genetic differentiation at the subspecies level is more pronounced, revealing clear genetic discontinuities between geographically isolated populations ${ }^{58,59,35}$.

The reasons for the relatively low genetic diversity of the peninsular pronghorn subspecies are unknown, with two (non-mutually exclusive) explanations being possible. The first of these is that human induced habitat loss, competition with domestic animals and uncontrolled hunting may have caused the peninsular pronghorn to decline over the past three centuries ${ }^{51,44}$, which may have been further exacerbated by small population sizes and inbreeding over the past few decades of captivity. Alternatively, or additionally, dramatic ecological changes during the last glacial maximum (LGM; ca. 12,000 years ago) resulted in the desertification of most of the Baja California peninsula, reducing water availability $60,61,62$ and likely contributing to a gradual reduction in pronghorn numbers over thousands of years.

Here, we generated a time series dataset of multilocus microsatellite data for the captive peninsular pronghorn spanning the period 2009 - 2021 inclusive. We first evaluated changes in genetic diversity, heterozygosity and inbreeding over the past 13 years. We then used approximate Bayesian computation $^{63}$ to evaluate support for alternative demographic scenarios that could explain the low genetic diversity of the peninsular pronghorn, and to estimate relevant parameters such as the current $N_{\mathrm{e}}$ and the strength and timing of historical declines. We hypothesised that the collapse of the peninsular pronghorn may have been driven by a combination of historical ecological changes and more recent anthropogenic factors. We furthermore hypothesised that, although the captive breeding programme has been successful in increasing the number of individuals, there may have been some unavoidable loss of genetic diversity and an increase in inbreeding over time, although we would expect that some of these changes will have been mitigated by the recent selective breeding attempt.

\section{Results}

\section{Summary statistics}

We genotyped 144 pronghorn individuals at 16 microsatellite loci. Our genotyping error rate, estimated from 12 samples genotyped at eight loci, was 0.03 per locus. The overall rate of missing data was $6.1 \%$, 
which fell to $4.6 \%$ when six individuals with missing data at four loci were excluded. Analysing the full dataset of 124 individuals (only fawns were included for 2012, 2016 and 2021; only adults were included for 2009 and 2018, Supplementary Table S1 online), we found significant deviations from HardyWeinberg equilibrium (HWE) at six loci (Supplementary Table S2 online). However, when the dataset was partitioned by year, we did not detect any consistent patterns of deviation from HWE across loci (Supplementary Table S2 online). Similar results were obtained for null alleles, with two loci (Aam1 and Anam6) showing indications of the presence of null alleles when all of the data were analysed together, while no consistent patterns were obtained when the years were analysed separately (Supplementary Table S3 online). Significant linkage disequilibrium (LD) was also detected for the full dataset $(p=0.02)$ but when the cohorts were analysed separately this was only present in $2009(p=0.01$, Supplementary Table S4 online). Consequently, we retained all of the microsatellite loci for subsequent analyses.

\section{Genetic diversity}

Among 124 captive peninsular pronghorn individuals genotyped at 16 microsatellite loci, we found a total of 88 alleles, with an overall mean number of alleles per locus of 5.5 (Table 1; Supplementary Table S5 online). Observed heterozygosity $\left(H_{o}\right)$ was slightly but not significantly (Bartlett's K-squared $=0.071, p=$ 0.79) lower than expected heterozygosity $\left(H_{e}\right)$ (Table 1; Supplementary Table S5 online). No significant differences among years were found for the basic diversity estimates (Supplementary Fig. S1 online), although $H_{O}$ and $H_{\mathrm{e}}$ showed a weak tendency to decline over time, with the highest values being observed in 2009 and the lowest values being observed in 2018 (Supplementary Fig. S1 online). 
Table 1

Mean values and $95 \%$ confidence intervals (in parentheses) of genetic diversity estimates for the captive peninsular pronghorn based on 16 microsatellite loci. Genetic diversity was evaluated for the complete dataset of 124 individuals as well as separately for each year. $N=$ number of individuals, $A=$ number of alleles, $A_{\mathrm{r}}=$ allele richness, $H_{\mathrm{e}}=$ expected heterozygosity, $H_{\mathrm{o}}=$ observed heterozygosity, IR = internal relatedness, $\mathrm{sMLH}=$ standardized multilocus heterozygosity, $\mathrm{HL}=$ homozygosity weighted by locus, and TrioML $=$ inbreeding index. $A, A_{\mathrm{r}}, H_{\mathrm{e}}$ and $H_{\mathrm{o}}$ were estimated by locus, whereas $\mathrm{sMLH}, \mathrm{HL}, \mathrm{IR}$ and TrioML are individual based estimates.

\begin{tabular}{|lllllll|}
\hline Diversity index & Year & \multicolumn{5}{l}{ Full dataset } \\
\cline { 2 - 6 } & $\mathbf{2 0 0 9}$ & $\mathbf{2 0 1 2}$ & $\mathbf{2 0 1 6}$ & $\mathbf{2 0 1 8}$ & $\mathbf{2 0 2 1}$ & \\
\hline$N$ & 18 & 33 & 45 & 19 & 9 & 124 \\
\hline$A$ & $3.4(0.70)$ & $3.8(0.81)$ & $3.8(1.0)$ & $3.7(0.92)$ & $3.0(0.65)$ & $5.5(1.21)$ \\
\hline$A_{\mathrm{r}}$ & $2.85(0.47)$ & $2.99(0.48)$ & $2.59(0.36)$ & $2.75(0.47)$ & $2.66(0.52)$ & $2.8(0.19)$ \\
\hline$H_{\mathrm{e}}$ & $0.51(0.10)$ & $0.53(0.08)$ & $0.46(0.06)$ & $0.45(0.09)$ & $0.46(0.11)$ & $0.51(0.06)$ \\
\hline$H_{\mathrm{o}}$ & $0.55(0.11)$ & $0.48(0.09)$ & $0.46(0.06)$ & $0.42(0.09)$ & $0.46(0.15)$ & $0.47(0.05)$ \\
\hline $\mathrm{IR}$ & $0.10(0.11)$ & $0.25(0.07)$ & $0.18(0.06)$ & $0.32(0.11)$ & $0.38(0.14)$ & $0.22(0.04)$ \\
\hline sMLH & $1.13(0.15)$ & $0.98(0.10)$ & $0.95(0.09)$ & $0.85(0.12)$ & $0.82(0.19)$ & $0.96(0.05)$ \\
\hline HL & $0.44(0.07)$ & $0.52(0.05)$ & $0.55(0.03)$ & $0.59(0.05)$ & $0.61(0.09)$ & $0.54(0.02)$ \\
\hline TrioML & $0.07(0.05)$ & $0.13(0.04)$ & $0.09(0.03)$ & $0.18(0.07)$ & $0.13(0.06)$ & $0.12(0.02)$ \\
\hline
\end{tabular}

\section{Heterozygosity and inbreeding}

Three frequency-weighted microsatellite-based measures of individual heterozygosity - standardized multilocus heterozygosity (sMLH), internal relatedness (IR) and homozygosity weighted by locus (HL) showed consistent trends of declining heterozygosity over time (all significant at $p<0.05$, Table 2 , Fig. $1 \mathrm{a}-\mathrm{c}$ ). Based on the TrioML inbreeding index, we found that the captive herd of peninsula pronghorn is moderately inbred, with $f$ averaging $0.12(95 \% \mathrm{Cl}=0.02)$ and ranging from zero to 0.53 (Fig. $1 \mathrm{~d}$ and Table 1). We also detected a significant increase in inbreeding over time (Table 2, Fig. 1e), which was mostly attributable to an increase in the proportion of moderately to highly inbred individuals $(f>0.125)$ from $16.6 \%$ in 2009 to $55.5 \%$ in 2021 (Fig. 1, Supplementary Table S6 online). 
Table 2

Results of the generalized linear mixed models (GLMMs) of the effect of years in captivity upon estimates of individual diversity and inbreeding index, based on different time intervals. Only significant $p$-values were highlighted in bold.

\begin{tabular}{|lllll|}
\hline Diversity estimate & Time interval & Random effect variance & Fixed effect estimate & $p$-value \\
\hline SMLH & $2009-2021$ & 0.00 & -0.085 & 0.002 \\
& $2009-2018$ & 0.00 & -0.088 & 0.006 \\
& $2018-2021$ & 0.00 & -0.039 & 0.82 \\
\hline IR & $2009-2021$ & 0.00 & 0.036 & 0.003 \\
& $2009-2018$ & 0.00 & 0.032 & 0.04 \\
& $2018-2021$ & 0.00 & 0.032 & 0.48 \\
\hline HL & $2009-2021$ & $1.962 \mathrm{e}-17$ & 0.144 & 0.0002 \\
& $2009-2018$ & 0.00 & 0.172 & 0.0004 \\
& $2018-2021$ & 0.00 & 0.027 & 0.82 \\
\hline TrioML & $2009-2021$ & $2.325 \mathrm{e}-19$ & 0.014 & 0.04 \\
& $2009-2018$ & 0.00 & 0.019 & 0.03 \\
& $2018-2021$ & $7.500 \mathrm{e}-20$ & -0.04 & 0.28 \\
\hline
\end{tabular}

To investigate whether the selective breeding attempt in 2018 could have helped to slow down the loss of heterozygosity, we compared regressions of $\mathrm{SMLH}, \mathrm{IR}, \mathrm{HL}$ and inbreeding index on time for the periods 2009-2018 and 2018-2021 (Fig. 1a-c, e, Table 2). All of the former were significant at $p<0.05$, whereas none of the latter were significant (Table 2). Although we do not have a sufficiently long time series after the selective breeding attempt to allow us to formally test for differences in the slopes, we did observe a tendency for the slopes to decrease after 2018, at least for SMLH and HL (Fig. 1a-c). Furthermore, the proportion of highly inbred offspring $(f>0.25)$ declined from $26.3 \%$ in 2018 to $11.1 \%$ in 2021 (Fig. $1 \mathrm{~d}$ and Supplementary Table $\mathrm{S} 6$ online). Accordingly, the predicted values from the GLMs based on data from 2009-2018 projected higher genetic erosion than was actually observed (Supplementary table S7 online).

\section{Historical demography.}

We used $A B C$ to evaluate four alternative historical scenarios (Supplementary Fig. S2 online and Methods section for details). The best supported model $(59 \%, \mathrm{Cl}=58-60 \%)$ contained both a historical and a recent reduction event, while the second-best supported model $(\sim 33 \%)$ contained only a recent reduction event. The prior predictive error was high (logistic approach, 0.56 ) but the posterior error was low at 0.39. Five demographic parameters were estimated for the best supported model (Fig. 2). Although posterior estimations for the contemporary and historical $N_{e}$ were wide, we observed a large, over 200 -fold 
decrease in the current $N_{\mathrm{e}}$ in comparison to the historical estimate (Fig. 2a-c). Assuming a pronghorn generation time of approximately two years ${ }^{64}$, we inferred that the first historical decline occurred approximately $6,000(95 \% \mathrm{Cl}=2,060-17,720)$ years ago, whereas second decline dated back to around $554(95 \% \mathrm{Cl}=7-2,420)$ years ago (Fig. 2 d,e).

\section{Discussion}

Our time-series genetic dataset represents an important resource for the conservation management of the peninsular pronghorn and has produced at least two significant discoveries. First, we were able to uncover a gradual genetic diversity erosion of the captive herd over time, although recent attempts at selective breeding appear to have partially mitigated this trend. Second, we could show that the genetic diversity of the peninsular pronghorn has been shaped by a combination of historical and recent demographic changes driven by the ecological transformation of the Baja California peninsula and by anthropogenic pressures including hunting and habitat destruction. Below, we discuss the relevance of these findings to peninsula pronghorn conservation.

The peninsular pronghorn experienced a severe decline during the last two centuries, from once being present across much of the Baja California peninsula to being functionally extinct in the wild ${ }^{51,52,59}$. This decline motivated the captive breeding program initiative ${ }^{44,53}$. The primary goal of any captive program is to create a self-sustaining population that may ultimately serve as a source of individuals for reintroductions or for augmenting existing wild populations ${ }^{65,66}$. In spite of early difficulties related to management, health problems and juvenile mortality ${ }^{67}$, by the end of 2021 and with approximately 700 individuals, the Peninsular Pronghorn Conservation Programme achieved this goal ${ }^{53}$. Until now, however, we lacked an understanding of how the last 13 years of captivity may have shaped the genetic composition of the captive herd.

Although we did not find any statistically significant temporal changes in several marker-based estimates of genetic diversity $\left(A, A_{n} H_{e}\right.$ and $\left.H_{o}\right)$, a tendency for reduction was observed for $H_{e}(9.8 \%$, from 0.51 in 2009 to 0.46 in 2021) and $H_{o}(16.3 \%$, from 0.55 in 2009 to 0.46 in 2021). Furthermore, all three estimates of individual heterozygosity ( $\mathrm{SMLH}, \mathrm{IR}$ and $\mathrm{HL}$ ) declined significantly during the course of the study with, for example, sMLH decreasing by around $27 \%$ over the past 13 years. This pattern was mirrored by the TrioML based inbreeding coefficient, which showed a gradual reduction in the number of non-inbred and weakly inbred individuals and a concurrent increase in the number of moderately to highly inbred individuals. These findings are consistent with the theoretical expectation of zygosity being a function of the breeding system. Thus, inbreeding directly reduces heterozygosity by increasing the proportion of homozygotes relative to random expectations, but only indirectly affects allelic richness. By contrast, genetic drift directly affects allelic diversity but only indirectly impacts heterozygosity ${ }^{68,69}$. Therefore, our results suggest that inbreeding is currently the predominant force shaping the genetic diversity of the peninsular pronghorn. 
The genetic management of captive populations has proven to be extremely effective in preventing the loss of genetic diversity and ameliorating the negative effects of inbreeding ${ }^{70,71,72}$. Accordingly, we found that the implementation of a selective breeding attempt in 2018 was associated with a slight reduction in the slope of the relationship between heterozygosity and time, as well as with a reduction in the proportion of highly inbred individuals. Furthermore, model-based predictions suggest that the 2021 offspring cohort is significantly more outbred than would be expected if no genetic management had been undertaken. Consequently, although it is still rather early to tell, our preliminary results suggest that this strategy might be beneficial in terms of mitigating inbreeding and the loss of heterozygosity.

While our results provide grounds for cautious optimism, a number of caveats should be born in mind. First, in our study, comparisons among different years were not always based on the same age class, with mainly fawns being sampled in 2012, 2016 and 2021, and mainly adults being sampled in 2009 and 2018. However, the difficulty of handling captive pronghorn meant that it was not possible to exhaustively sample both age classes across all years. We therefore focused on sampling adults at the beginning of the study and in the year of the selective breeding attempt in order to provide reference populations against which subsequent generations of offspring could be compared. We do not believe that having sampled different age classes negates our main findings as we controlled for this statistically in our GLMMs. Furthermore, estimates of inbreeding increased between adults sampled in 2009 and 2018, while the offspring cohorts sampled in 2012, 2016 and 2021 also showed trends of decreasing heterozygosity and increasing inbreeding over time.

Second, although previous studies of the american pronghorn subspecies have documented inbreeding depression for multiple traits from birth mass through fawn survival to body condition ${ }^{73}$, we do not currently know if inbreeding has negative fitness consequences in the peninsular pronghorn. Therefore, future studies should aim to evaluate the extent of inbreeding depression in this subspecies, as well as to evaluate whether temporal changes in the amount of inbreeding are associated with changes in the mean fitness of the population. Over longer timescales, a handful of microsatellites cannot tell us very much about the nature or magnitude of functional genetic variation, although neutral genetic diversity should in general provide a rough indication of the adaptive potential of a given species ${ }^{74}$. Nonetheless, we believe that the recent sequencing of the pronghorn genome ${ }^{75}$ will facilitate more detailed investigation of how unintended selection and drift may have impacted the genetic composition of the peninsula pronghorn. In particular, dense single nucleotide polymorphisms mapped to the reference genome could be used to characterize runs of homozygosity, identical by descent haplotypes that are informative both about inbreeding and population history ${ }^{76}$. Furthermore, computational approaches have been developed to infer the presence of putatively deleterious alleles from whole genome resequencing data 77,78 . Application of these approaches to pronghorn would shed light on the genetic load and its relationship to historical demography both within and across species.

Finally, it should be born in mind that developing a selective breeding programme over the longer term and extending it to the entire captive pronghorn herd would bring significant challenges. Currently, the 
peninsular pronghorn population is kept in large enclosures, with the smallest of these housing the pregnant females, spanning a total of around 100 ha. Therefore, the size of the pens places limits on the scope of intensive management actions. The captive handling of pronghorns also carries an increased risk of serious injury to the animals, especially as this species is susceptible to capture myopathy ${ }^{79,80,81}$. Finally, captive breeding and genetic management require access to financial resources ${ }^{82}$. Consequently, pronghorn managers will need to weigh all of the pros and cons to design and implement a genetic management programme that is optimized for this species and which is feasible given financial and logistical constraints.

Characterizing the strength and timing of historical declines can provide insights into the causes of those declines and thereby help conservation practitioners to create conditions that promote population recovery ${ }^{83}$. Based on our demographic reconstruction of the peninsular pronghorn, we inferred that the onset of the decline may have been linked to climatic changes at the end of the LGM and the ensuing desertification of the Baja California peninsula. This is not surprising given that the contraction of open woodlands and expansion of desert scrub after the last glaciation are believed to be responsible for multiple extinction events as well as shifts in the geographical distributions of many animal species on the Baja California peninsula $84,85,86$. Furthermore, droughts have been recognized as one of the most important factors affecting the recruitment, mortality and abundance of pronghorns in arid and semi-arid areas $^{87,88,89}$. For example, a devastating drought in 2002 reduced the number of sonoran pronghorns in the USA to just 21 animals, motivating a captive breeding initiative as well as the introduction of animals from Mexico ${ }^{48,90}$. Consequently, our findings are consistent with the argument that precipitation is one of the most important factors limiting the abundance and geographical distribution of the pronghorn ${ }^{62}$.

Our demographic analysis also uncovered evidence for a more recent decline dating back around five hundred years ago. This is supported by recent studies showing that peninsular pronghorn numbers have decreased to fewer than 100-150 individuals over the past hundred years or so ${ }^{44,51}$. Our results therefore point towards a scenario involving two stepwise declines, the first mediated by climate related vegetation changes on the Baja California peninsula and the second driven by increasing anthropogenic pressures such as hunting, fencing and cattle ranching. Both climatic and anthropogenic stressors will likely continue to be a significant threat to the peninsular pronghorn in the coming decades ${ }^{44,53,62}$. In this regard, species abundance models could be a useful tool for identifying suitable areas for future reintroductions based on a combination of human threats and climatic projections. Moreover, genetic information could be used to optimally select individuals for release in such a way as to minimize inbreeding and maximise genetic diversity ${ }^{7,91}$.

To conclude, we investigated changes in heterozygosity and inbreeding over time in the captive peninsular pronghorn herd and used demographic reconstruction to evaluate alternative hypotheses relating to the decline of this subspecies. We found that, although the captive population has become progressively more inbred over time, selective breeding appears to have been beneficial in mitigating these trends. We could also show that this species probably experienced a gradual, protracted decline 
with two consecutive phases linked respectively to environmental change and anthropogenic impacts. Although the peninsular pronghorn still faces multiple threats, the success of the captive breeding programme at building a large and demographically stable population may hint at unexpected resilience, and is a clear testament to the success of ongoing protection measures.

\section{Method}

\section{Research permissions and ethical considerations}

All samples were collected by the management team of the Peninsular Pronghorn Conservation Programme under the registration key DGVS-UMA-VL-3755-BC given to the management unit by the Mexican Secretariat of Environment and Natural Resources. All procedures were approved by the authorized personal of the Valle de los Cirios Flora and Fauna Protection Area and followed the guidelines of the American Society of Mammalogists

(www.mammalsociety.org/uploads/committee_files/CurrentGuidelines.pdf, accessed 7 January 2022). This work did not require any approval from the ethical committee since no experiments on live animals were performed, aside from the routine tagging that was performed according to the conservation programme internal schedule. All procedures were in compliance with the ARRIVE guidelines for how to report animal experiments ${ }^{92}$.

\section{Sample collection}

Tissue samples were collected from 144 peninsular pronghorn individuals by trained personal during 2009-2021 from The Vizcaino Biosphere Reserve and Valle de los Cirios Flora and Fauna Protection Area (Supplementary Table S1 online). Small pieces of ear tissue were taken during the tagging and from deceased animals whenever those were found by the management team. Tissue samples were preserved in $100 \%$ ethanol at room temperature until processing. Samples were mainly taken from young individuals (newborns to animals up to six months of age) and occasionally from adults in 2012, 2016 and 2021, while in 2009 adults were sampled as a reference group. We additionally sampled adults in 2018 as part the selective breeding attempt described above. Those individuals were used as a breeding herd, with unrelated individuals preferentially selected as mating partners. Consequently, our sampling scheme spans 13 consecutive years out of the 23 years of the captive breeding programme.

\section{Molecular techniques}

DNA extractions were performed using DNeasy Blood \& Tissue Kit (Qiagen Inc., Valencia CA, USA) following the manufacturer's protocol. DNA concentration was determined using a NanoDrop2000 and each extract was adjusted to a concentration of approximately $100 \mathrm{ng} / \mathrm{ul}$. We amplified 16 microsatellite loci previously described for pronghorn ${ }^{93,94,95}$ using M13 genotyping strategy ${ }^{96}$. Additionally, 12 samples were independently re-genotyped at eight microsatellites in order to estimate our genotyping error rate. Polymerase chain reactions were carried out in an $11.5 \mathrm{uL}$ volume containing $1 \mathrm{uL}$ of the DNA template,

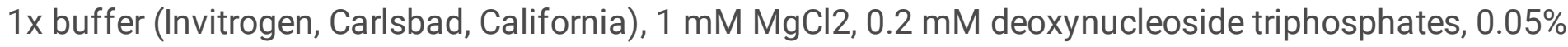


bovine serum albumin, $0.5 \mathrm{U}$ of Taq DNA Polymerase (Invitrogen), and $0.5 \mathrm{uM}$ of each primer. The polymerase chain reaction profile consisted of an initial denaturalization step at $95^{\circ} \mathrm{C}$ for $5 \mathrm{~min}$, followed by 35 cycles of $60 \mathrm{~s}$ each at $95^{\circ} \mathrm{C}$, annealing by ramping from 55 to $60^{\circ} \mathrm{C}$, followed by $60 \mathrm{~s}$ extension at $72{ }^{\circ} \mathrm{C}$. Cycles were terminated with a final extension stage of $10 \mathrm{~min}$ at $72^{\circ} \mathrm{C}$. PCR products were resolved on an Applied Biosystems 3730XL capillary sequencer at the University of Arizona Gene Core Facility and alleles were scored using PeakScanner v1.0 (Applied Biosystems).

\section{Data analysis.}

Genotypes were binned to size classes using FlexiBin ${ }^{97}$. After that, we imported the binned microsatellite data into the $\mathrm{R}$ environmen ${ }^{98}$ ( $\mathrm{R}$ version 4.1.2) and converted it into a GENIND object using adegenet ${ }^{99}$. We quantified the amount of missing data per locus and per individual using the R package poppr ${ }^{100}$ and removed all individuals that failed to genotype at four or more loci. We also used package PopGenReport ${ }^{101}$ to estimate null allele frequencies according to ${ }^{102}$. To test for linkage disequilibrium (LD) between pairs of loci, we used poppr. For this analysis, we used the standardized index of association (rbarD) ${ }^{103}$ and the number of permutations was specified using the 'sample $=999$ ' argument. We further tested for Hardy-Weinberg equilibrium using the pegas package ${ }^{104}$. All of the above analyses were performed on the complete dataset and separately for each year. Whenever multiple tests we used, the resulting $p$-values were adjusted for the false discovery rate (FDR) using R package $\operatorname{stats}^{98}$.

\section{Genetic diversity and summary statistics.}

The number of alleles $(A)$, allelic richness $\left(A_{r}\right)$, expected heterozygosity $\left(H_{e}\right)$ and observed heterozygosity $\left(H_{0}\right)$ were calculated for the full dataset and separately for each year using the R packages adegenet ${ }^{99}$ and hierfstat ${ }^{105}$. Multilocus heterozygosity was quantified as standardized multilocus heterozygosity (sMLH), internal relatedness (IR) and homozygosity weighted by locus $(\mathrm{HL})^{106}$ using R packages $R h h^{107}$ and inbreed $R^{108}$. We used COANCESTRY v. $1.0^{109}$ to calculate the inbreeding coefficient using the TrioML method ${ }^{110}$, using 10,000 reference individuals and bootstrapping on 10,000 samples. Following ${ }^{111}$, we designated inbreeding coefficients ( $f$ ) of zero as 'none', below 0.125 as 'low', $0.125 \geq f<0.25$ as 'moderate', and $f \geq 0.25$ as 'high'. Wilcox tests were then used to test for significant differences in the diversity indices using $\mathrm{R}$ package stats. We also used generalized linear mixed effect models (GLMMs) to quantify the strength of diversity decline over the years using the R package $I m e 4^{112}$. We accounted for the different age categories (fawns/adults) by specifying age as a random effect. Finally, using the "predict" function in the R package stats and the slope of the GLM spanning 2009-2018, we determined the modeled value for each diversity estimate assuming that no genetically based selective breeding programme had been implemented.

\section{Demographic reconstruction.}


To investigate the demographic history of the peninsular pronghorn, we used approximate Bayesian computation (ABC) as implemented in DIYABC v. 2.063,113,114 . For modeling alternative demographic histories and reconstructing demographic trajectories, we used data from 58 samples (fawns and adults) from 2016, which was the year represented by the largest number of individuals.

$A B C$ allows the evaluation of alternative demographic scenarios, expressed as a stepwise series of population size changes, and then uses summary statistics from the observed and simulated datasets to estimate parameter values and to assess the relative support for each scenario. We first developed four alternative demographic models intended to describe plausible patterns of effective population size $\left(N_{\mathrm{e}}\right)$ change over time. Priors for the timing of events and the magnitude of changes of $N_{\mathrm{e}}$ (Supplementary Fig. S2 online and Supplementary Table S8 online) were based on known events in the demographic history of the species, including environmental change on the peninsular after the LGM, anthropogenically induced population reduction and the captive breeding program ${ }^{42,60,61}$. The first scenario represented the null hypothesis of (a) constant $N_{\mathrm{e}}$ over time; the alternative scenarios invoked: (b) recent reduction caused by overexploitation and habitat loss, (c) historical reduction caused by the desertification of the Baja California peninsula, and (d) a combination of recent and historical reductions, expressed as a two-step model (Supplementary Fig. S2 online). After simulating one million datasets for each scenario, we used a polychotomous logistic regression procedure ${ }^{115}$ to estimate the posterior probability of each scenario based on the $1 \%$ of simulated data sets for each model that produced summary statistics closest to the observed values. The error rate was estimated using prior data space and the posterior distributions. The posterior error rate represents a proportion of wrongly identified scenarios over the 1,000 test datasets ${ }^{63}$. Based on the best supported scenario, local linear regression was used to estimate the posterior distributions of the parameters. Specifically, a logit transformation of parameter values was performed and the $1 \%$ closest simulated datasets to the observed were used for regression and posterior parameter estimation ${ }^{115}$.

\section{Declarations}

\section{Acknowledgments}

This work was partially funded by the Espacios Naturales y Desarrollo Sustentable A.C. (ENDESU). Support for the Article Processing Charge was granted by the Deutsche Forschungsgemeinschaft and the Open Access Publication Fund of Bielefeld University. We are thankful to the management team of Valle de los Cirios Flora and Fauna Protected Area, in particular to José Martín Gutiérrez Perea and Fernando Escoto Rodríguez. We are also thankful to Dr. Santiago Sanchez-Ramirez for his valuable comments that helped improve this manuscript.

\section{Author Contributions}

A.K. and J.I.H. designed the study; A.K and J.N.G.R. conducted the lab work and data analyses, A.K. and J.I.H. wrote the manuscript; A.K, J.N.G.R. and V.S.S. commented on and approved the final manuscript. 


\section{Data availability}

Our microsatellite dataset is available from the corresponding author on request or from Zenodo repository, https://doi.org/10.5281/zenodo.6014746

\section{Competing Interests Statement}

The authors declare no competing interests.

\section{References}

1. Butchart, S. H. M. et al. Global Biodiversity: indicators of recent declines. Science. 328 (5982), 11641168. https://doi.org/10.1126/science.1187512 (2010).

2. Dirzo, R. et al. Defaunation in the Anthropocene. Science. 345 (6195), 401-406. https://doi.org/10.1126/science.1251817 (2014).

3. Bradshaw, C. J. A. et al. Underestimating the challenges of avoiding a ghastly future. Front. Conserv. Sci. 1. https://doi.org/10.3389/fcosc.2020.615419 (2021).

4. Barnosky, A. D. et al. Has the Earth's sixth mass extinction already arrived? Nature. 471 (7336), 5157. https://doi.org/10.1038/nature09678 (2011).

5. Ceballos, G. et al. Accelerated modern human-induced species losses: Entering the sixth mass extinction. Sci. Adv. 1(5). https://doi.org/10.1126/sciadv.1400253 (2015).

6. Ceballos, G., Ehrlich, P. R. \& Raven, P. H. Vertebrates on the brink as indicators of biological annihilation and the sixth mass extinction. Proc. Natl. Acad. Sci. U.S.A. 117 (24), 13596-13602. https://doi.org/10.1073/pnas.1922686117 (2020).

7. McGowan, P. J., Traylor-Holzer, K. \& Leus, K. IUCN guidelines for determining when and how ex situ management should be used in species conservation. Conserv. Lett.10(3), 361-366. https://doi.org/10.1111/conl.12285 (2016).

8. Clout, M. N. \& Merton, D. V. Saving the Kakapo: the conservation of the world's most peculiar parrot. Bird Conser. Int. 8 (3), 281-296. https://doi.org/10.1017/s0959270900001933 (1998).

9. Milinkovitch, M. C. et al. Genetic analysis of a successful repatriation programme: giant Galápagos tortoises. Proc. Royal Soc. B P ROY SOC. B-BIOL. SCI. 271 (1537), 341-345. https://doi.org/10.1098/rspb.2003.2607 (2004).

10. Ryder, O. A. \& Wedemeyer, E. A. A cooperative breeding programme for the Mongolian wild horse Equus przewalskii in the United States. Biol. Conserv. 22(4), 259-271 https://doi.org/10.1016/00063207(82)90021-0 (1982).

11. Mallinson, J. J. C. Conservation breeding programmes: an important ingredient for species survival. Biodivers. Conserv. 4 (6), 617-635 https://doi.org/10.1007/bf00222518 (1995).

12. Seddon, P. J., Armstrong, D. P. \& Maloney, R. F. Developing the science of reintroduction biology. Conserv. Biol. 21 (2), 303-312. https://doi.org/10.1111/j.1523-1739.2006.00627.x (2007). 
13. Bowkett, A. E. Recent captive-breeding proposals and the return of the ark concept to global species conservation. Conserv. Biol. 23(3), 773-776. https://doi.org/10.1111/j.1523-1739.2008.01157.x (2009).

14. Shan, L. et al. Large-scale genetic survey provides insights into the captive management and reintroduction of giant pandas. Mol. Biol. Evol. 31(10), 2663-2671.

https://doi.org/10.1093/molbev/msu210 (2014).

15. Fischer, J. \& Lindenmayer, D. An assessment of the published results of animal relocations. Biol. Conserv. 96 (1), 1-11. https://doi.org/10.1016/s0006-3207(00)00048-3 (2014).

16. Christie, M. R., Marine, M. L., French, R. A. \& Blouin, M. S. Genetic adaptation to captivity can occur in a single generation. Proc. Natl. Acad. Sci. U.S.A. 109(1), 238-242.

https://doi.org/10.1073/pnas.1111073109 (2011).

17. Fraser, D. J. et al. Population correlates of rapid captive-induced maladaptation in a wild fish. Evol. Appl. 12 (7), 1305-1317 https://doi.org/10.1111/eva.12649 (2018).

18. Ralls, K., Brugger, K. \& Ballou, J. Inbreeding and Juvenile Mortality in Small Populations of Ungulates. Science. 206 (4422), 1101-1103. https://doi.org/10.1126/science.493997 (1979).

19. Charlesworth, D. \& Charlesworth, B. Inbreeding depression and its evolutionary consequences. Annu. Rev. Ecol. Evol. Syst. 18(1), 237-268. https://doi.org/10.1146/annurev.es.18.110187.001321 (1987).

20. Ralls, K., Ballou, J. D. \& Templeton, A. Estimates of lethal equivalents and the cost of inbreeding in mammals. Conserv. Biol. 2(2), 185-193. https://doi.org/10.1111/j.1523-1739.1988.tb00169.x (1988).

21. Hedrick, P. W. \& Kalinowski, S. T. Inbreeding depression in conservation biology. Annu. Rev. Ecol. Evol. Syst. 31 (1), 139-162. https://doi.org/10.1146/annurev.ecolsys.31.1.139 (2000).

22. Frankham, R. Introduction to Conservation Genetics 2nd edition (Cambridge University Press, 2010).

23. Laikre, L. Conservation genetics of nordic carnivores: lessons from zoos. Hereditas. 130 (3), 203216. https://doi.org/10.1111/j.1601-5223.1999.00203.x (2004).

24. Gomendio, M., Cassinello, J. \& Roldan, E. R. S. A comparative study of ejaculate traits in three endangered ungulates with different levels of inbreeding: fluctuating asymmetry as an indicator of reproductive and genetic stress. Proc. Royal Soc. B P ROY. SOC. B-BIOL. SCI. 267(1446), 875-882. https://doi.org/10.1098/rspb.2000.1084 (2000).

25. Swinnerton, K. J., Groombridge, J. J., Jones, C. G., Burn, R. W. \& Mungroo, Y. Inbreeding depression and founder diversity among captive and free-living populations of the endangered pink pigeon Columba mayeri. Anim. Conserv. 7(4), 353-364.https://doi.org/10.1017/s1367943004001556 (2004).

26. Farquharson, K. A., Hogg, C. J. \& Grueber, C. E. Offspring survival changes over generations of captive breeding. Nat. Commun. 12(1). https://doi.org/10.1038/s41467-021-22631-0 (2021).

27. Kleiman, D. G., Thompson, K., V. \& Baer, C. K. Wild mammals in captivity: principles and techniques for zoo management 2nd edition (University of Chicago Press, 2021). 
28. Ralls, K. \& Ballou, J. D. Captive breeding and reintroduction in Encyclopedia of Biodiversity (ed. Levin, S. A.) 662-667 (Academic Press, 2013). https://doi.org/10.1016/b978-0-12-384719-5.00268-9

29. Reed, D. H. \& Frankham, R. Correlation between fitness and genetic diversity. Conserv. Biol. 17 (1), 230-237. https://doi.org/10.1046/j.1523-1739.2003.01236.x (2003).

30. Spielman, D., Brook, B. W. \& Frankham, R. Most species are not driven to extinction before genetic factors impact them. Proc. Natl. Acad. Sci. U.S.A. 101(42), 15261-15264.

https://doi.org/10.1073/pnas.0403809101 (2003).

31. Willi, Y., van Buskirk, J. \& Hoffmann, A. A. Limits to the adaptive potential of small populations. Annu. Rev. Ecol. Evol. Syst. 37(1), 433-458. https://doi.org/10.1146/annurev.ecolsys.37.091305.110145 (2006).

32. Habel, J. C., Husemann, M., Finger, A., Danley, P. D. \& Zachos, F. E. The relevance of time series in molecular ecology and conservation biology. Biol. Rev. 89(2), 484-492. https://doi.org/10.1111/brv.12068 (2013).

33. Araki, H., Cooper, B. \& Blouin, M. S. Genetic effects of captive breeding cause a rapid, cumulative fitness decline in the wild. Science. 318 (5847), 100-103. https://doi.org/10.1126/science.1145621 (2007).

34. Purohit, D. et al. Genetic effects of long-term captive breeding on the endangered pygmy hog. PeerJ. 9 e12212. https://doi.org/10.7717/peerj.12212 (2021).

35. Hahn, E. E. \& Culver, M. Genetic diversity and structure in Arizona pronghorn following conservation efforts. Conserv. Sci. Pract. 3 (10) https://doi.org/10.1111/csp2.498 (2021).

36. Charlesworth, B. Effective population size and patterns of molecular evolution and variation. Nat. Rev. Gen. 10 (3), 195-205 https://doi.org/10.1038/nrg2526 (2009).

37. Wang, J., Santiago, E. \& Caballero, A. Prediction and estimation of effective population size. Heredity. 117(4), 193-206 https://doi.org/10.1038/hdy.2016.43 (2016).

38. O'Gara, W., Yoakum, J. D. \& McCabe, R. E. Pronghorn: Ecology and Managment (University Press of Colorado, 2004).

39. Janis, C. M., Scott, K. M. \& Jacobs, L. L. Evolution of Tertiary Mammals of North America: Volume 1, Terrestrial Carnivores, Ungulates, and Ungulate like Mammals. (Cambridge University Press, 2005).

40. Nelson, E. W. Status of the pronghorn antelope, 1922 - 1924. U.S. Department Agriculture Bulletin 1346, Washington, D.C., USA 1925.

41. O'Gara, B. W. \& R. E. McCabe. From exploitation to conservation in Pronghorn: ecology and management (eds. O'Gara, B. W. \& Yoakum, J. D.) 41-73 (University Press Colorado, 2004).

42. Cancino, J., Ortega-Rubio, A. \& Sanchez-Pacheco, J. A. Status of an endangered subspecies: the peninsular pronghorn at Baja California. J. Arid Environ. 32(4), 463-467. https://doi.org/10.1006/jare.1996.0039 (1996).

43. Laliberte, A. S. \& Ripple, W. J. Range Contractions of North American carnivores and ungulates. BioScience. 54(2), 123-138. https://doi.org/10.1641/0006-3568 (2004). 
44. Medellín, R. A. et al. History, ecology, and conservation of the pronghorn antelope, bighorn sheep, and black bear in Mexico in Biodiversity, Ecosystems, and Conservation in Northern Mexico (eds. Cartron J.-L., Ceballos G. \& Felger R. S.) 387-405 (Oxford University Press, 2005.)

45. Lee, T. E., Bickham, J. W. \& Scott, M. D. Mitochondrial DNA and allozyme analysis of North American pronghorn populations. J. Wildl. Manag. 58 (2), 307-318. https://doi.org/10.2307/3809396 (1994).

46. IUCN SSC Antelope Specialist Group. Antilocapra americana ssp. peninsularis. The IUCN Red List of Threatened Species 2021: e.T1679A200726719. https://dx.doi.org/10.2305/IUCN.UK.2021 -2.RLTS.T1679A200726719.en (2021).

47. SEMARNAT. Norma Oficial Mexicana NOM-059-SEMARNAT-2010, Protección ambiental- Especies nativas de México de flora y fauna silvestres-Categorías de riesgo y especificaciones para su inclusión, exclusión o cambio- Lista de especies en riesgo. Diario Oficial de la Federación 30 diciembre, 2010. (2010).

48. U. S. Fish and Wildlife Service. Recovery Plan for the Sonoran pronghorn (Antilocapra americana sonoriensis), Second Revision. (U.S. Fish and Wildlife Service, Southwest Region, Albuquerque, New Mexico, USA, 2016).

49. Cancino, J., Sanchez-Sotomayor, V. \& Castellanos, R. From the Field: Capture, hand-raising, and captive management of peninsular pronghorn. Wildl. Soc. Bull. 33(1), 61-65. https://doi.org/10.2193/0091-7648 (2005).

50. Horne, J. S., Hervert, J. J., Woodruff, S. P. \& Mills, L. S. Evaluating the benefit of captive breeding and reintroductions to endangered Sonoran pronghorn. Biol. Conserv. 196, 133-146. https://doi.org/10.1016/j.biocon.2016.02.005 (2016).

51. CONANP. Programa de Acción para la Conservación de la Especie: Berrendo (Antilocapra americana), 2009 año del berrendo. Secretaria del Medio Ambiente y Recursos Naturales (SEMARNAT). México D. F. (2009).

52. Cancino, J., Rodríguez-Estrella, R. \& Miller, P. Using population viability analysis for management recommendations of the endangered endemic peninsular pronghorn. Acta Zool. Mex. 26 (1) (2010).

53. Danoff-Burg J. A. \& K Mulroe 2021. Peninsular Pronghorn Species Action Plan. In Press.

54. Stephen, C. L. et al. Population genetic analysis of sonoran pronghorn (Antilocapra americana sonoriensis). J. Mammal. 86(4), 782-792. https://doi.org/10.1644/1545-1542 (2005a).

55. Stephen, C. L., Whittaker, D. G., Gillis, D., Cox, L. L. \& Rhodes, O. E. Genetic consequences of reintroductions: an example from oregon pronghorn antelope (Antilocapra americana). J. Wildl. Manag. 69(4), 1463-1474. https://doi.org/10.2193/0022-541x (2005b).

56. Barnow-Meyer, K. \& Byers, J. Genetic diversity and gene flow in Yellowstone Basin pronghorn (Antilocapra americana). The UW National Parks Service Research Station Annual Reports. 31, 6572. https://doi.org/10.13001/uwnpsrc.2008.3705 (2008).

57. LaCava, M. E. F. et al. Pronghorn population genomics show connectivity in the core of their range. J.Mammal. 101(4), 1061-1071. https://doi.org/10.1093/jmammal/ gyaa054 (2020). 
58. Klimova, A., Munguia-Vega, A., Hoffman, J. I. \& Culver, M. Genetic diversity and demography of two endangered captive pronghorn subspecies from the Sonoran Desert. J. Mammal. 95(6), 1263-1277. https://doi.org/10.1644/13-mamm-a-321 (2014).

59. Hahn, E. E., Klimova, A., Munguía-Vega, A., Clark, K. B. \& Culver, M. Use of museum specimens to refine historical pronghorn subspecies boundaries. J. Wildl. Manag. 84(3), 524-533. https://doi.org/10.1002/jwmg.21810 (2020).

60. Axelrod, D.I. The evolution of desert vegetation in western North America. Carnegie Instit. Wash. Publ. 590, 215-306 (1950).

61. Dolby, G. A., Bennett, S. E. K., Lira-Noriega, A., Wilder, B. T. \& Munguía-Vega, A. Assessing the geological and climatic forcing of biodiversity and evolution Surrounding the Gulf of California. J. Southwest. 57, 391-455. https://doi.org/10.1353/jsw.2015.0005 (2015).

62. Gedir, J. V., Cain, J. W., Harris, G. \& Turnbull, T. T. Effects of climate change on long-term population growth of pronghorn in an arid environment. Ecosphere. 6(10), art189. https://doi.org/10.1890/es1500266.1 (2015).

63. Cornuet, J. M. et al. DIYABC v2.0: a software to make approximate Bayesian computation inferences about population history using single nucleotide polymorphism, DNA sequence and microsatellite data. Bioinformatics. 30 (8), 1187-1189. https://doi.org/10.1093/bioinformatics/btt763 (2014).

64. Hahn, E. E. \& Culver, M. Genetic diversity and structure in Arizona pronghorn following conservation efforts. Conserv. Sci. Pract. 3(10). https://doi.org/10.1111/csp2.498 (2021).

65. Soule, M. E. Conservation Biology: The Science of Scarcity and Diversity. (Sinauer Associates Inc, 1986).

66. Ballou, J. D. \& Foose, T.J. Demographic and genetic management of captive populations. in Wild Mammals in Captivity (eds. Kleiman, D. G., Allen, M., Thompson, K., Lumpkin, S. \& Harris, H.) 263283 (Chicago, IL: University of Chicago Press, 2012).

67. Islas-Espinoza, M. \& de las Heras, A. Peninsular Pronghorn Conservation: Too Many Paradigms, Too Few Indicators in Sustainability Indicators in Practice (eds. Latawiec, A. \& Agol, D.) 126-145 (De Gruyter Open Poland 2015) 10.1515/9783110450507-012.

68. Crow, J.F. \& Kimura, M. An introduction in population genetics theory (Harper and Row, New York, 1970)

69. Falconer, D.S. Introduction to quantitative genetics. 3rd edition,(Longman Scientific and Technical, New York, 1989).

70. Ballou, J. D. Strategies for maintaining genetic diversity in captive populations through reproductive technology. Zoo Biol. 3 (4), 311-323 https://doi.org/10.1002/zoo. 1430030404 (1984).

71. Ballou, J.D. \& Lacy, R.C. Identifying genetically important individuals for management of genetic diversity in pedigreed populations in Population management for survival and recovery (eds. Ballou, J.D., Gilpin M. \& Foose T.J.) 76-111 (New York: Columbia Press, 1995).

72. Montgomery, M. E. et al. Minimizing kinship in captive breeding programs. Zoo Biol. 16(5), 377-389. https://doi.org/10.1002/(sici)1098-2361 (1997). 
73. Dunn, S. J., Clancey, E., Waits, L. P. \& Byers, J. A. Inbreeding depression in pronghorn (Antilocapra americana) fawns. Mol. Ecol. 20 (23), 4889-4898. https://doi.org/10.1111/j.1365294x.2011.05327.x (2011).

74. Kardos, M. et al. The crucial role of genome-wide genetic variation in conservation. Proc. Natl. Acad. Sci. U.S.A. 118 (48). e2104642118. https://doi.org/10.1073/pnas.2104642118 (2021).

75. Zoonomia Consortium. A comparative genomics multitool for scientific discovery and conservation. Nature. 587(7833), 240-245. https://doi.org/10.1038/s41586-020-2876-6 (2020).

76. Ceballos, F. C., Joshi, P. K., Clark, D. W., Ramsay, M. \& Wilson, J. F. Runs of homozygosity: windows into population history and trait architecture. Nat. Rev. Genet. 19(4), 220-234. https://doi.org/10.1038/nrg.2017.109 (2018).

77. Supple, M. A. \& Shapiro, B. Conservation of biodiversity in the genomics era. Genome Biol. 19(1). https://doi.org/10.1186/s13059-018-1520-3 (2018).

78. Hohenlohe, P. A. \& Rajora, O. P. Population Genomics: Wildlife. (Springer Publishing, 2020).

79. Chalmers, G.A. \& Barrett MW. Capture myopathy in pronghorns in Alberta, Canada. J. Am. Vet. Med. Assoc. 171(9), 918-923. (1977).

80. Sotelo-Gallardo, H., Contreras Balderas, A. J. \& Espinosa Treviño, A. Comparación de dos métodos de liberación del berrendo, Antilocapra americana (Artiodactyla: Antilocapridae) en Coahuila, México. Rev. Biol. Trop. 65 (3), 1208. https://doi.org/10.15517/rbt.v65i3.29447 (2017).

81. Breed, D. et al. Conserving wildlife in a changing world: Understanding capture myopathy-a malignant outcome of stress during capture and translocation. Conserv. Physiol. 7(1). https://doi.org/10.1093/conphys/coz027 (2019).

82. Snyder, N. F. et al. Limitations of captive breeding in endangered species recovery. Conserv. Biol. 10 (2), 338-348. https://doi.org/10.1046/j.1523-1739.1996.10020338.x (1996).

83. Bonebrake, T. C., Christensen, J., Boggs, C. L. \& Ehrlich, P. R. Population decline assessment, historical baselines, and conservation. Conserv. Lett. 3(6), 371-378. https://doi.org/10.1111/j.1755263x.2010.00139.x (2010).

84. Grismer, L. L. \& McGuire, J. A. The oases of central Baja California, Mexico. Part I. A preliminary account of the relict mesophilic herpetofauna and the status of the oases. Bull. - South. Calif. Acad. Sci. 92, 2-24 (1993).

85. Welsh, H. H., Clark, W. H., Franco-Vizcaíno, E. \& Valdéz-Villavicencio, J. H. Herpetofauna associated with palm oases across the Californian-Sonoran transition in Northern Baja California, Mexico. Southwest. Nat. 55(4), 581-585. https://doi.org/10.1894/pas-15.1 (2010).

86. Mann, D. H., Groves, P., Gaglioti, B. V. \& Shapiro, B. A. Climate-driven ecological stability as a globally shared cause of Late Quaternary megafaunal extinctions: the Plaids and Stripes Hypothesis. Biol. Rev. 94(1), 328-352. https://doi.org/10.1111/brv.12456 (2018).

87. Brown, D. E., Warnecke, D. \& McKinney, T. Effects of midsummer drought on mortality of doe pronghorn (Antilocapra americana). Southwest. Nat. 51(2), 220-225. https://doi.org/10.1894/00384909 (2006). 
88. Simpson, D. C., Harveson, L. A., Brewer, C. E., Walser, R. E. \& Sides, A. R. Influence of precipitation on pronghorn demography in Texas. J. Wildl. Manag. 71(3), 906-910. https://doi.org/10.2193/2005753 (2007).

89. McKinney, T., Brown, D. E. \& Allison, L. Winter Precipitation and Recruitment of pronghorns in Arizona. Southwest. Nat. 53(3), 319-325. https://doi.org/10.1894/cj-147.1 (2008).

90. Otte A. Partners save the Sonoran pronghorn. Endang. Species Bull. 31, 22-23 (2006).

91. McCullough, D. R. \& Barrett, R. H. Wildlife 2001: Populations (Springer, 1992).

92. Percie Du Sert, N. et al. Reporting animal research: Explanation and elaboration for the ARRIVE guidelines 2.0. PLOS Biol. 18(7), e3000411. https://doi.org/10.1371/journal.pbio.3000411. (2020).

93. Carling, M. D., Passavant, C. W. \& Byers, J. A. DNA microsatellites of pronghorn (Antilocapra americana). Mol. Ecol. Not. 3(1), 10-11. https://doi.org/10.1046/j.1471-8286.2003.00334.x (2002).

94. Dunn, S. J. et al. Ten polymorphic microsatellite markers for pronghorn (Antilocapra americana). Conserv. Genet. Resour. 2(1), 81-84. https://doi.org/10.1007/s12686-009-9166-9 (2010).

95. Munguia-Vega, A., Klimova, A. \& Culver, M. New microsatellite loci isolated via next-generation sequencing for two endangered pronghorn from the Sonoran Desert. Conserv. Genet. Resour. 5(1), 125-127. https://doi.org/10.1007/s12686-012-9749-8 (2012).

96. Boutin-Ganache, I., Raposo, M., Raymond, M. \& Deschepper, C. F. M13-Tailed primers improve the readability and usability of microsatellite analyses performed with two different allele-sizing methods. BioTechniques. 31(1), 25-28. https://doi.org/10.2144/01311bm02 (2001).

97. Amos, W. et al. Automated binning of microsatellite alleles: problems and solutions. Mol. Ecol. Not. 7(1), 10-14. https://doi.org/10.1111/j.1471-8286.2006.01560.x (2006).

98. R Core Team. R: A language and environment for statistical computing. R Foundation for Statistical Computing, Vienna, Austria. URL https://www.R-project.org/ (2021).

99. Jombart, T. \& Ahmed, I. adegenet 1.3-1: new tools for the analysis of genome-wide SNP data. Bioinformatics. 27(21), 3070-3071 https://doi.org/10.1093/bioinformatics/ btr521 (2011).

100. Kamvar, Z. N., Tabima, J. F. \& Grünwald, N. J. Poppr: an R package for genetic analysis of populations with clonal, partially clonal, and/or sexual reproduction. PeerJ. 2, e281. https://doi.org/10.7717/peerj.281 (2014).

101. Adamack, A. T. \& Gruber, B. PopGenReport: simplifying basic population genetic analyses in R. Methods Ecol. Evol. 5(4), 384-387. https://doi.org/10.1111/2041-210x.12158 (2014).

102. Agapow, P. M. \& Burt, A. Indices of multilocus linkage disequilibrium. Mol. Ecol. Not. 1(1-2), 101102. https://doi.org/10.1046/j.1471-8278.2000.00014.x (2001).

103. Brookfield, J. F. Y. A simple new method for estimating null allele frequency from heterozygote deficiency. Mol. Ecol. 5(3), 453-455 (1996). https://doi.org/10.1111/j.1365-294x.1996.tb00336.x

104. Agapow, P. M. \& Burt, A. Indices of multilocus linkage disequilibrium. Mol. Ecol. Not. 1, 101-102ю https://doi.org/10.1046/j.1471-8278.2000.00014.x (2001). 
105. Paradis, E. pegas: an R package for population genetics with an integrated-modular approach. Bioinformatics. 26(3), 419-420. https://doi.org/10.1093/ bioinformatics/btp696 (2010).

106. Goudet, J. hierfstat, a package for $r$ to compute and test hierarchical F-statistics. Mol. Ecol. Not. 5(1), 184-186. https://doi.org/10.1111/j.1471-8286.2004.00828.x (2005).

107. Aparicio, J. M., Ortego, J. \& Cordero, P. J. What should we weigh to estimate heterozygosity, alleles or loci? Mol. Ecol. 15(14), 4659-4665. https://doi.org/10.1111/j.1365-294x.2006.03111.x (2006).

108. Alho, J. S., Välimäki, K. \& Merilä, J. Rhh: an R extension for estimating multilocus heterozygosity and heterozygosity-heterozygosity correlation. Mol. Ecol. Res. 10(4), 720-722. https://doi.org/10.1111/j.1755-0998.2010.02830.x (2010).

109. Stoffel, M. A. et al. inbreedR: an R package for the analysis of inbreeding based on genetic markers. Methods Ecol. Evol. 7(11), 1331-1339. https://doi.org/10.1111/2041-210x.12588 (2016).

110. Wang, J. coancestry: a program for simulating, estimating and analysing relatedness and inbreeding coefficients. Mol. Ecol. Res. 11(1), 141-145. https://doi.org/10.1111/j.1755-0998.2010.02885.x (2010).

111. Wang, J. Triadic IBD coefficients and applications to estimating pairwise relatedness. Genet. Res. 89(3), 135-153. https://doi.org/10.1017/s0016672307008798 (2007).

112. Marshall, T. C. et al. Estimating the prevalence of inbreeding from incomplete pedigrees. Proc. Royal Soc. B P ROY SOC. B-BIOL. SCI. 269(1500), 1533-1539 https://doi.org/10.1098/rspb.2002.2035 (2002).

113. Bates, D., Mächler, M., Bolker, B. \& Walker, S. (Fitting Linear Mixed-Effects Models Using Ime4. J. Stat. Softw. 67(1). https://doi.org/10.18637/jss.v067.i01 (2015).

114. Beaumont, M. A., Zhang, W. \& Balding, D. J. Approximate Bayesian Computation in population genetics. Genetics. 162(4), 2025-2035. https://doi.org/10.1093/genetics/162.4.2025 (2002).

115. Bertorelle, G., Benazzo, A. \& Mona, S. ABC as a flexible framework to estimate demography over space and time: some cons, many pros. Mol. Ecol. 19(13), 2609-2625. https://doi.org/10.1111/j.1365-294x.2010.04690.x (2010).

116. Fagundes, N. J. R. et al. Statistical evaluation of alternative models of human evolution. Proc. Natl. Acad. Sci. U.S.A. 104(45), 17614-17619 https://doi.org/10.1073/pnas.0708280104 (2007).

\section{Figures}

\section{Figure 1}

Violin plots showing temporal changes in heterozygosity and inbreeding in the captive peninsular pronghorn. Panels (a) to (c) show changes in three frequency weighted measures of individual heterozygosity: standardized multilocus heterozygosity (sMLH), internal relatedness (IR) and 
homozygosity weighted by locus $(\mathrm{HL})$ respectively. Panel (d) shows bar charts depicting the proportion (\%) of individuals falling within different inbreeding classes, from none $(f=0)$, through low $(f=<0.125)$ and moderate $(0.125<f<0.25)$ to high $(f>0.25)$, as estimated using TrioML. Panel (e) shows violin plots of changes in the inbreeding coefficient, estimated using TrioML. In panels (a) to (c) and (e), the boxplots span the first to third quartiles, with horizontal lines inside the boxes representing the medians. The raw data are plotted as black points and the black lines connecting the boxplots correspond to regression lines smoothed and fitted with the "glm" function separately for the years 2009-2018 and 2018-2021.

\section{Figure 2}

Posterior density curves and numerical estimates of demographic parameters for the best supported demographic scenario, which contains both a historical and a more recent reduction. (a) historical effective population size; (b) effective population size before the recent demographic reduction; (c) current effective size of the captive peninsular pronghorn herd; $(d)$ the number of generations since the historical demographic reduction; and (e) the number of generations since the recent demographic reduction. Panel (f) shows the mean, mode and $95 \%$ confidence intervals of each estimated demographic parameter.

\section{Supplementary Files}

This is a list of supplementary files associated with this preprint. Click to download.

- Supplementarylnformation.pdf 